\title{
IMPLEMENTASI INFRASTRUKTUR JARINGAN BERBASIS CLOUD DI SMKN 01 MOOTILANGO
}

\author{
Hariyono N Jainahu ${ }^{1}$, Alimuddin Yasin ${ }^{2}$, Irwan Karim ${ }^{3}$ \\ 1,2,3 Teknik Informatika Politeknik Gorontalo \\ E-mail: *11 hariyono.mhs14@ti.poligon.ac.id, ${ }^{2}$ alimuddiny@poligon.ac.id, ${ }^{3}$ irwankarim@poligon.ac.id
}

\begin{abstract}
ABSTRAK - Banyaknya permintaan penggunaan sumber daya dalam proses pendidikan yang tidak mencukupi membuat proses pembelajaran kurang maksimal dan optimal. Kurangnya dana mejadi salah satu penghambat untuk memenuhi infrastruktur sumber daya yang dibutuhkan, hadirnya teknologi cloud computing kini menjadi pilihan dalam membangun infrastruktur jaringan komputer yang lebih mudah. Banyak yang mulai menggunakan teknologi ini karena banyaknya keuntungan yang dapat diperoleh. Fitur-fitur yang disediakan oleh teknologi cloud memberikan kontribusi besar terhadap efisiensi, efektifitas bahkan hingga ke penurunan biaya investasi dan operasional IT, Keuntungan diatas diantaranya dapat diperoleh dengan menerapkan salah satu infrastruktur cloud yakni Infrastructure as a Service(IaaS) sebagai infrastruktur perangkat keras dan virualisasi yang siap digunakan. Dalam penelitian ini kami membangun sebuah infrastruktur berbasis cloud untuk memaksimalkan pemanfaatan mesin-mesin berkapasitas multicore dan banyak memory untuk digunakan secara efektif pada banyak service dalam jaringan dengan menggunakan teknik virtualisasi berbasis openstack. Hasilnya adalah sebuah konfigurasi jaringan berbasis cloud yang diimplementasikan pada laboratoriumsekolah SMK.
\end{abstract}

Kata Kunci : Cloud Computing, OpenStack, Mesin Virtual.

\section{PENDAHULUAN}

Dalam proses belajar materi kejuruan para siswa dituntut untuk dapat mempraktekan ilmunya langsung ke perangkat keras. Dengan jumlah siswa yang banyak serta penggunaan yang besar maka kebutuhan sumber daya perangkat keras semakin tinggi. Di SMK N 01 Mooilango jumlah perangkat keras yang tersedia hanya sedikit, sehingga tidak memenuhi jumlah kebutuhan siswa.

Kurangnya sumber daya perangkat keras pada proses pendidikan membuat proses pembelajaran tidak maksimal ketika digunakan dalam skala banyak dan bersamaan. Penambahan perangkat keras hanya menambah biaya sehingga bukan menjadi solusi yang tepat. Pengadaan sumber daya barupun akan memakan banyak waktu dan proses yang lama.
Berdasarkan hasil survei di SMKN 01 Mootilango, terdapat 4 komputer dengan spesifikasi yang mencukupi, 2 diantaranya sedang aktif dipakai dan 2 lainnya dapat digunakan sebagai infrastruktur cloud. Setelah peneliti melakukan analisis, didapatkan hasil untuk membuat infrastruktur cloud dengan memanfaatkan 2 buah komputer untuk memaksimalkan penggunaannya dengan merancang infrsatruktur cloud yang lebih menghemat efisiensi waktu dan biaya untuk pemenuhan sumber daya.

Dengan mengimplementasikan teknologi cloud computing openstack sebagai infratruktur jaringan, diharapkan dapat mengurangi efisiensi waktu dan biaya maintanance server. Teknologi cloud computing merupakan model komputasi dimana sumber daya seperti processor, storage, network dan software sebagai sebuah layanan, dan teknologi cloud computing merupakan pengembangan teknologi virtualisasi (Purbo, 2011)

\section{a. Rumusan Masalah}

Rumusan masalah yang akan digunakan sebagai acuan dalam penelitian:

1. Bagaimana mengimplementasikan infrastruktur jaringan berbasis cloud?

b. Tujuan

Tujuan yang ingin dicapai dalam penelitian ini adalah: 1. Dapat mengimplementasikan cloud sebagai infrastruktur jaringan. c. Manfaat

Adapun manfaat yang diharapkan dari penelitian ini adalah hasil penelitian berguna sebagai informasi dalam mengimplementasikan cloud computing menggunakan OpenStack

\section{d. Batasan Masalah}

2. Sistem ini dibangun dari 2 buah komputer.

3. Server menggunakan sistem operasi Linux distro Ubuntu 14.04.05 LTS.

4. Komputer remote menggunakan layanan ssh sebagai remote server.

5. Perangkat lunak OpenStack digunakan untuk membangun Cloud Computing. 
6. Image virtual Ubuntu 12.04.02 yang digunakan untuk membangun instance.

7. OpenStack yang dibangun digunakan untuk menerapkan layanan Infrastructure as a Service (IaaS)

\section{LANDASAN TEORI}

\section{A. CloudComputing}

Cloud Computing adalah sebuah model komputasi dimana sumber daya seperti daya komputasi, penyimpanan, jaringan dan perangkat lunak disediakan sebagai layanan di internet (Rahma et al., 2014).

\section{B. Infrastructure as a Service (IaaS)}

Infrastructure as a Service (IaaS) adalah layanan dari cloud computing yang menawarkan perangkat keras komputer sebagai layanan yang dapat disewakan. Perangkat keras yang ditawarkan seperti : storage, server dan ruangpusat data (Mell, Grance, \& Grance, 2012)

\section{OpenStack}

OpenStack adalah teknologi cloud computing yang menyediakan sistem operasi cloud untuk public dan private cloud di bawah Apache License. Saat ini telah didukung oleh lebih dari 60 perusahaan yang berkontribusi untuk mengembangkan teknologi ini(Putu Gede Surya Cipta Nugraha, I Komang Ari Mogi, 2015).

\section{Open Stack Compute Service(Nova)}

Teknologi ini terdiri dari serangkaian proyek yang saling terkait dengan Open source Software yang di desain untuk me-manage jaringan-jaringan skala besar, virtual mesin serta menciptakan platform yang scalable untuk cloud-computing (Ardianto \& Sumaryono, 2012).

\section{E. Open Stack Imaging Service(Glance)}

OpenStack Imaging Service adalah sebuah pencarian dan pengambilan sistem untuk mesin virtualimage (virtual machine images) (Moh. Supriadi, 2013). Hal ini dapat dikonfigurasi untuk menggunakan salah satu dari backends penyimpanan (storage backends)

\section{F. Open Stack Storage Service(Swift)}

Swift mampu menyimpan miliaran objek yang didistribusikan di seluruh node. Swift sudah built-in sistem redundansi dan manajemen failover dan mempunyai kemampuan untuk mengarsipkan dan media streaming. Hal ini sangat scalable baik dari segi ukuran (several petabyte) dan kapasitas (number of objects) (Moh. Supriadi, 2013).

\section{G. OpenStackIdentity Service (Keystone)}

Keystone menyediakan layanan identitas dan akses kebijakan untuk semua komponen dalam keluarga OpenStack. Keystone menerapkan itu di REST-nya sendiri yang berbasis API (Identity API). Keystone menyediakan otentikasi dan otorisasi untuk semua komponen OpenStack termasuk (namun tidak terbatas pada) Swift, Glance, Nova. Otentikasi memverifikasi bahwa sebuah permintaan itu sebenarnya berasal dari siapa yang mengakatakan itu tidak. Otorisasi akan memverifikasi apakah pengguna yang terotentikasi memiliki akses ke layanannya yang dia minta (Moh. Supriadi, 2013).

\section{H. Open Stack UI Service (Horizon)}

Horizon dashboard berbasis web dapat digunakan untuk mengelola / mengatur layanan OpenStack. Hal ini dapat digunakan untuk mengelola instances dan images, membuat keypairs, melampirkan volume ke instance, memanipulasi Swift container dll. Selain itu, dashboard bahkan memberikan akses pengguna kekonsol instance dan dapat terhubung ke sebuah instance melalui VNC (Moh. Supriadi, 2013).

\section{METODE PENELITIAN}

Penelitian ini menggunakan metodologi eksperimen yang terdiri dari 9 (sembilan) tahapan, ditunjukkan pada Gambar 3.1.

\section{$\mathbf{z} \longrightarrow \longrightarrow$ \\ Gambar 1. Tahapan Metodologi Eksperimen (Ernawati, 2013)}

Tahap pertama melakukan kajian induktif, merupakan metode pemikiran yang bertolak dari kaidah (hal-hal atau peristiwa) khusus untuk menentukan kaidah yang umum. Dalam penelitian ini dilakukan secara deduktif untuk mempermudah pemahaman peneliti. Kajian deduktif dilakukan dengan mengkaji tentang layanan cloud computing secara umum selanjutnya secara khusus dikaji mengenai perkembangan penggunaan layanan IaaS di berbagi bidang khususnya bidang pendidikan serta mengkaji tools apa saja yang dapat digunakan untuk membangun sistem IaaS. Setelah dilakukan kajian deduktif tahap berikutnya yaitu mengidentifikasikan permasalahan dan melakukan studi literatur terkait topik penelitian.

Tahap selanjutnya yaitu perencanaan penelitian, pada tahap iniditentukan objek dan pembuatan instrumen penelitian. Objek penelitian ini mengambil studi kasus di salah satu instasi dinas komunikasi dan informatika provinsi gorontalo. Instrumen penelitian dibuat untuk memperoleh data di lapangan yang akan dipergunakan untuk membangun dan menguji sistem. Instrumen penelitian yang dibuat dalam penelitian ini yaitu instrumen wawancara yang digunakan untuk memperoleh data tentang kebutuhan pengguna dan 
instrumen pengujian yang digunakan untuk menguji prototype IaaS yang telah dibanguan.Pada tahap uji coba dilakukan perancangan, pembangunan Sistem.

\section{HASIL DAN PEMBAHASAN}

\section{Perancangan Sistem}

Sistem yang akan dibangun terdiri dari dua buah serverdan satu klien. Serverpertama akan berfungsi sebagai Cloud Controller (CLC), Cluster Controller (CC), Storage Controller (SC), dan Walrus Storage Controller. Server kedua akan difungsikan sebagai Node Controller (NC). Kliendigunakan untuk mengkonfigurasi sistem. Konfigurasi yang akan dibangun seperti pada tabel 1 .

Tabel 1. Konfigurasi sistem

\begin{tabular}{|c|c|c|}
\hline Deskripsi & Server 1 & Server 2 \\
\hline Fungsi & $\begin{array}{l}\text { nova, } \\
\text { glance, } \\
\text { keystone } \\
\text { dan horizon. }\end{array}$ & nova \\
\hline NIC & enp2s1 & enp5s1 \\
\hline IP Address & $\begin{array}{l}\text { enp2s1- } \\
10.42 .0 .37 / 2 \\
4\end{array}$ & $\begin{array}{l}\text { enp5s1- } \\
10.42 .0 .38 / 2 \\
4\end{array}$ \\
\hline Hostname & controller & node \\
\hline DNS & 8.8 .8 .8 & 8.8.8.8 \\
\hline Gateway & 10.42 .0 .1 & 10.42 .0 .1 \\
\hline
\end{tabular}

Pada konfigurasi sistem, server pertama akan dipasang satu Network Interface Card (NIC). IP address untuk enps2s1 server pertama adalah 10.42.0.37 dengan subnet mask 255.255.255.0. Alamat ini yang akan digunakan untuk akses utama menuju sistem.Serverkedua yang berlaku sebagai node memiliki satu NIC yang digunakan untuk berkomunikasi dengan serverpertama. IP address yangdigunakan adalah 10.42.0.38 dengan subnet mask 255.255.255.0. Remote klienakan digunakan untuk melakukan konfigurasi sistem cloud, pembuatan images, pengaturan images, pengaturan menjalankan instance, serta untukpemeliharaan sistem cloud bagi admin. Untuk pengaturan IP address client akan menggunakan Static IP.

Pada tabel 2 merupakan serangkaian teknologi yang diapakai dalam pembuatan infrastruktur cloud. Teknologi tersebut dibangun di atas host.

Tabel 2. Teknologi yang digunakan dalam membangun

\begin{tabular}{|c|c|}
\hline \multicolumn{2}{|c|}{ cloud } \\
\hline & Implementasi \\
\hline Message queue & RabbitMQ 2.7.1.0 \\
\hline \multirow{2}{*}{ Virtualisasi } & Libvirt \\
\hline & KVM \\
\hline
\end{tabular}

\begin{tabular}{|c|c|}
\hline Basis data & MySQL 5.5.3 \\
\hline Web Server & Apache 2.2.22 \\
\hline $\begin{array}{c}\text { Network } \\
\text { Manager }\end{array}$ & FlatDHCP \\
\hline
\end{tabular}

\section{A. Topologi Jaringan}

1. Topologi Sistem

Topologi infrastruktur yang akan dibangun seperti pada gambar 2

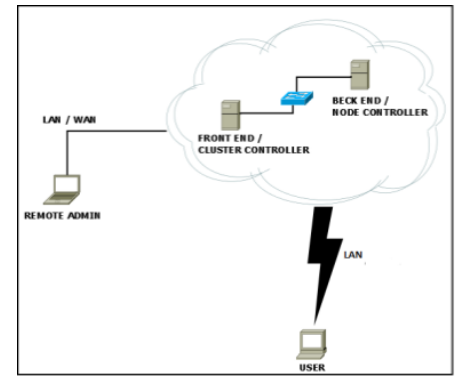

Gambar 2. Topologi IaaS yang akan dibangun

Sistem cloud yang akan dibangun, terdiri dari dua buah server dan berada pada satu network yang sama. Sedangkan untuk Remote kliendapat mengakses server Front End dan Back End untuk keperluan administrasi. User mengakses sistem melalui jaringan LAN (Local Area Network).

2. Proses Instalasi

Secara garis besar tahapan instalasi keseluruhan terlihat seperti gambar 3 .

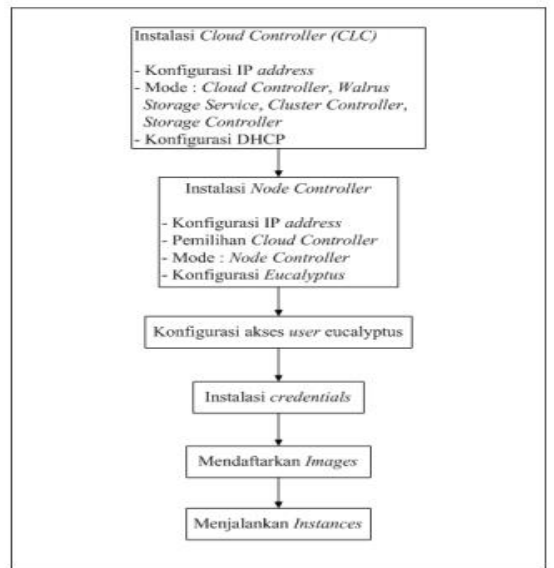

Gambar 3. Diagram alir instalasi sistem cloud IaaS

Tahapan pertama kali dilakukan adalah mengecek ketersediaan sumber daya pada Node Controller. Hal ini dilakukan untuk memastikan berapa jumlah server virtual yang dapat dibuat dalam sistem. Tahap berikutnya adalah mengecek ketersediaan images untuk pembuatan server. Apabila belum tersedia, images dapat diunduh melalui situs penyedia images cloud. Perintah running instances dijalankan untuk membuat instance dengan spesifikasi yang 
telah ditentukan berdasarkan image yang dipilih, apabila telah selesai, perintah terminate instance dilakukan untuk mematikan instance.

\section{Implementasi Sistem}

Setelah melakukan melakukan semua konfigurasi kebutuhan pengguna pada server, langkah selanjutnya penulis memeriksa service-service yang telah berjalan agar penggunaan sumber daya akan maksimal. Untuk dapat menjalankan mesin virtual yang banyak dan bersamaan, Pastikan kedua server telah telah terhubung dan menjalankan service-servicecloud. Selanjutnya penulis memanggil service pada nova untuk melihat servis yang sedang berjalan yaitu memanggil perintah :

- nova-manage service-list

Perintah tersebut digunakan untuk mengetahui servis yang aktif pada layanan cloud. Service tersebut terdiri dari nova-cert, nova-compute, nova-consoleauth, novanetwork, nova-volume dan nova scheduler.

\section{B. Dashboard}

Pengujian dilakukan dengan membangun mesin virtual yang dilakukan di dashboard.

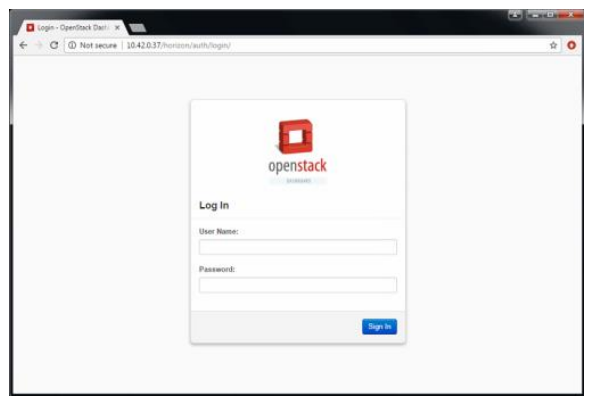

Gambar 4. Tampilan awal dashboard

Gambar 4. merupakan tampilan awal login pada dashboard/horizon. Dashboard akan menampilkan layananlayanan yang disediakan oleh admin.

\section{Instance}

Merupakan tampilan untuk menbuat dan melihat mesin virtual yang akan digunakan. Pada tampilan user admin, terlihat seluruh instance yang dibuat oleh semua user dashboardseperti pada gambar 5 berikut.

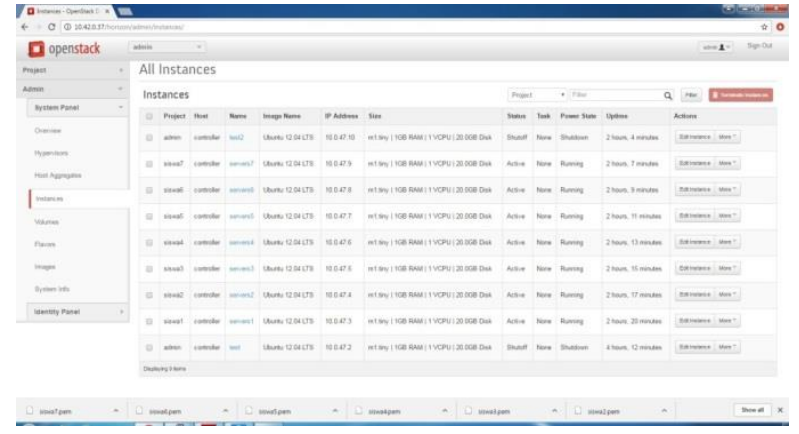

Gambar 5. Instance

D. Flavors

Mesin virtual yang dijalankan dibuat terlebih dahulu kebutuhan perangkatnya. Mesin virtual tersebut dibangun di flavors yang akan dijalankan oleh instance seperti pada gambar 6 .

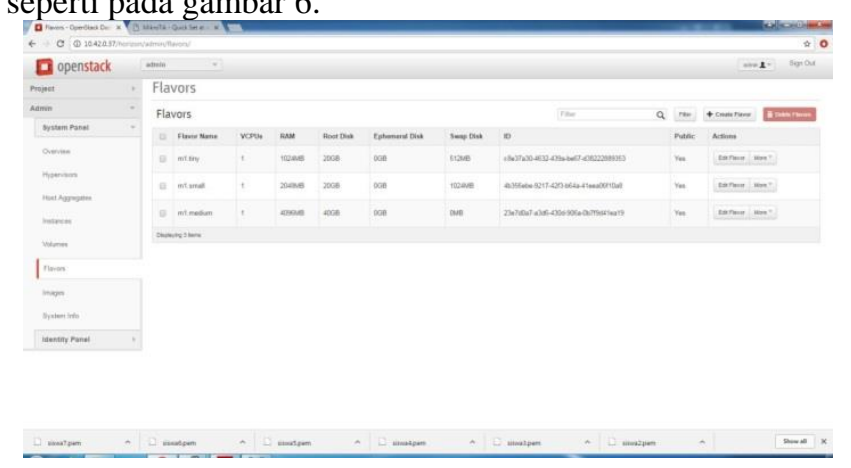

Gambar 6. Flavors

E. Overview

Menampilkan jumlah sumber daya yang bisa digunakan oleh user tertentu dan sebelumnya telah dibatasi penggunaanya oleh admin pada menu project seperti pada gambar 7.

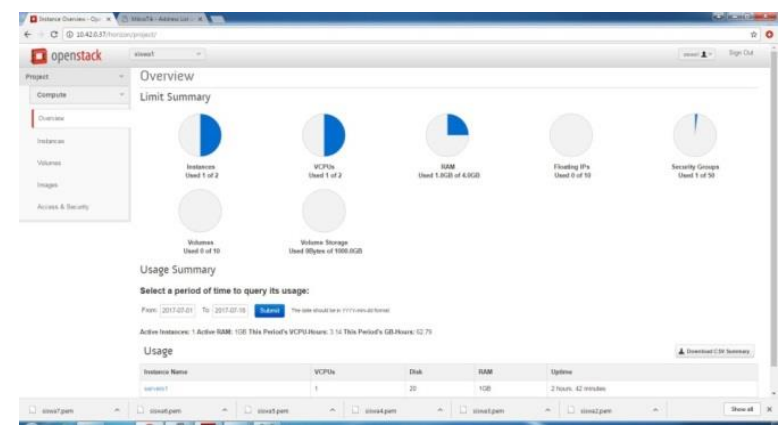

Gambar 7. Overview pada user siswa1 


\section{F. Hypervisors}

Merupakan tampilan untuk melihat komputer yang sedang dipakai dalam membangun cloud. Hypervisors menampilkan jumlah sumber daya yang dipakai seperti VCPU, Memory dan Disk Usage.

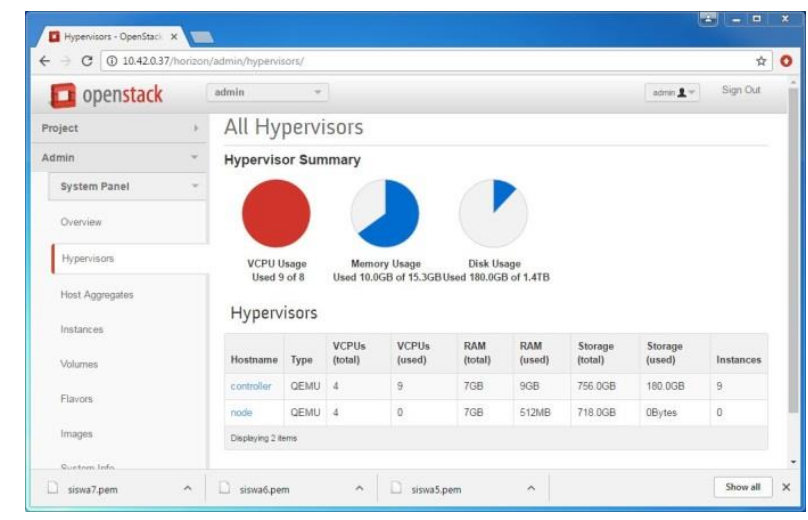

Gambar 8 Hypervisors

Dari hasi gambar 8 bahwa instance yang dapat dibuat sebanyak 16 dengan memaksimalkan penggunaan core processor dan virtual processor, pemakain memory rata-rata 1GB dan diskspace 20GB pada kedua server, yaitu controller dan node. Pemakaian sumber daya dapat diubah untuk memaksimalkan penggunaan memory dan disk space untuk kebutuhan lainnya.

\section{KESIMPULAN DAN SARAN}

\section{Kesimpulan}

Penulis menyimpulkan dari hasil analisa dan pembahasan bahwa:

1. Dari pengujian yang dilakukan didapatkan hasil server yang dimiliki oleh SMKN 01 Mootilango mampu untuk diimplementasikan sebagai server cloud computing. Dengan implementasi ini server dapat digunakan sebagai infrastruktur jaringan berbasis cloud dengan teknik virtualisasi.

2. Sumber daya komputasi dapat diakses oleh pengguna melalui web browser dan remote SSH.

3. Image yang dibuat menggunakan sistem operasi Ubuntu 12.0 LTS dengan format qcow2.

4. Kedua node dapat menjalankan 16 buah instance secara bersamaan dengan memaksimalkan kinerja CPU.

Saran

Adapun saran yang dapat diberikan sehubungan dengan pelaksanaan penelitian ini adalah:
1. Infrastruktur cloud ini dapat dikembangkan lagi dengan menggunakan mesin virtual yang telah menjadi sebuah layanan berbasis aplikasi.

2 Dalam pengembangannya, infrastruktur cloud dapat dibangun lebih daari multi node.

3. Jika menggunakan dan menjalankan lebih banyak service pada server cloud, semakin banyak inti prosesor dan semakin besarkapasitas $R A M$ yang digunakan akan lebih baik dalam kestabilan server cloud secara keseluruhan

\section{DAFTAR PUSTAKA}

Ardianto, N., \& Sumaryono, S. (2012). Pengembangan Virtual Appliance Server Dengan Metode Virtualisasi, 1(1), 18-23.

Ernawati, T. (2013). Analisis dan Pembangunan Infrastruktur Cloud Computing. Jurnal Cybermatika, 1(2), 17-23.

Mell, P., Grance, T., \& Grance, T. (2012). The NIST Definition of Cloud Computing Recommendations of the National Institute of Standards and Technology.

Moh. Supriadi, A. I. M. (2013). Analisis Performance Cloud Computing Berbasis Platform as a Service (PaaS) Dengan Eucalyptus System dan Openstack Pada Ubuntu Server.

Purbo, O. W. (2011). Petunjuk Praktis Cloud Computing Mengunakan Open Source, 1-48.

Putu Gede Surya Cipta Nugraha, I Komang Ari Mogi, I. M. A. S. (2015). Implementasi Private Cloud Computing Sebagai Layanan Infrastructure As a Service ( Iaas ). Studi, Program Informatika, Teknik Komputer, Jurusan Ilmu, 8(2), 7-14.

Rahma, N. F. P., Rochim, A. F., \& Widianto, E. D. (2014). Analisis Implementasi Infrastructure as A Service Menggunakan Ubuntu Cloud Infrastruktur. Jurnal Teknologi Dan Sistem Komputer, 2(1), 79-86. https://doi.org/10.14710/JTSISKOM.2.1.2014.79-86 